\title{
Ion-Mobility Mass Spectrometry of Glycans and Glycopeptides Us- ing Both Intact and Glycan Sequencing Approaches In Positive Ion Mode Facilitates Glycan Isomer and Glycan Motif Identification
}

\author{
Edward G. Pallister ${ }^{\dagger \dagger}$ Matthew S. F. Choo ${ }^{\dagger}$, Ian Walsh ${ }^{\dagger}$, Jien-Nee Tai ${ }^{\dagger}$, Shi-Jie Tay ${ }^{\dagger}$, Yuansheng Yang ${ }^{\dagger}$, \\ Say-Kong $\mathrm{Ng}^{\dagger}$, Pauline M. Rudd ${ }^{\dagger}$, Sabine L. Flitsch ${ }^{\text {+*}^{*}}$ and Terry Nguyen-Khuong ${ }^{\dagger *}$
}

†Bioprocessing Technology Institute, Agency for Science Technology and Research, Singapore

$\ddagger$ School of Chemistry \& Manchester Institute of Biotechnology (MIB), The University of Manchester, United Kingdom

Supporting Information Placeholder

\begin{abstract}
High resolution glycan analysis has become an important part of biopharmaceutical API production and quality control. Liquid chromatography (LC) is now a well-established technique in this field but the resolution of similar isomeric glycan structures is still a challenge. Here we show that the addition of ion mobility spectroscopy (IMS) in a hyphenated LC-IMS-MS setting allows for the high resolution of $\mathrm{N}$-glycan isomers during positive ion analysis. We have identified unique features in the IM chromatograms to help differentiate a range of isomeric $\mathrm{N}$-glycans for both RFMS labelled glycans and glycopeptides.
\end{abstract}

\section{Introduction}

Glycans are post translational modifications (PTMs) found on many proteins and lipids. Glycans play a key role in human and animal cell biology, ranging from cell signaling, to increasing protein stability. ${ }^{1}$ Glycans differ from other PTMs in that they are composed from a wide range of carbohydrate building blocks and contain diverse and complex structural motifs. ${ }^{2}$ There is an ever increasing interest in the role and function of glycans and the need to understand how different structural motifs influence biological processes. Interest in glycan analysis has increased further, since the advent of glycosylated protein biologics to treat a variety of diseases. ${ }^{3}$ Glycosylation is fundamental to the biopharma industry where it serves as a critical quality attribute to many current and new biologics. ${ }^{4}$ For example, the degree of overall galactosylation and fucosylation of Immunoglobulin G can drive the immunological response down the complement $(\mathrm{C} 1 \mathrm{q})$ pathway or the antibody dependent cellular cytotoxicity (ADCC) pathway. ${ }^{5,6}$ Additionally, the presence of an $\alpha$-1,3-galactosyl epitope on some antibody-based drugs can induce severe immune responses as a consequence of the glycans being present on the biologic. ${ }^{7}$

The importance of understanding the glycans present on biologics means that analytical methods that can easily deduce complex glycan structures are of increasing importance. Mass Spectrometry (MS) is a common analytical tool to characterize glycans and carbohydrate motifs by identifying unique mass to charge ratios $(\mathrm{m} / \mathrm{z})$ to determine a glycan structure. A variety of MS glycomic approaches have been shown to be powerful tools for analyzing complex mixtures of glycans. ${ }^{8}$ Mass spectrometry is restricted in that isomeric glycan structures (different structures with the same $\mathrm{m} / \mathrm{z}$ ) cannot be easily distinguished by MS alone. Therefore, glycan MS analysis is often combined with liquid chromatography (LC) to separate glycan isomers prior to being passed to the MS, known as LC-MS.

LC-MS allows for improved identification of glycan isomers of the same mass, by initially separating different glycan structures during LC and identifying retention time (RT) values for the glycans. Identification of glycans can then be confirmed based on a combination of the glycan's $\mathrm{m} / \mathrm{z}$ and RT. A range of different LC stationary phases have been shown to be useful for separation of glycans and these have been extensively reviewed by others such as L. Habja et $\mathrm{al}^{9}$ and also L. Veillon et al. ${ }^{10}$ Methods to normalize the RT of glycans using glucose units (GUs) for hydrophilic interaction chromatography (HILIC) has helped to standardize LC based glycomic methodologies. ${ }^{11}$ Despite this, without the application of orthogonal methods such as exoglycosidases ${ }^{12,13}$, it is still very challenging to characterize glycans quickly with a high degree of unambiguity using LC-MS.

Due to the issues surrounding LC-MS glycomic analysis researchers have looked to adding an extra dimension of analysis in the form of ion mobility spectrometry (IMS) to help achieve accurate identification of glycans. ${ }^{14}$ IMS allows for the determination of a collision cross sectional area (CCS) of a molecular ion in the gas phase during MS analysis. The CCS is derived from the length of time an ion travels through an IMS drift tube. ${ }^{15}$ The CCS values can be used as an additional point of data for confirming a glycan structure. This has most notably been demonstrated by the ability to differentiate between $\alpha 2,3$ and $\alpha 2,6$ sialic acid glycan motifs by K. Pagel et al. ${ }^{16}$ D. Harvey et al ${ }^{17,18}$ have also demonstrated in negative ion MS analysis of glycans, a large number of glycan motifs that are identifiable using IMS. Negative ion analysis of glycans has to date shown limited success for analysis of glycopeptides, which slightly restricts the scope of the negative ion approach as a ubiquitous analytical method for both released glycomics and glycproteomics. ${ }^{19,20}$

Currently the most commonly used approaches for IMS-MS analysis of glycans can be put into two categories (as highlighted by Scheme 1). The first approach is an intact IMS-MS analysis 


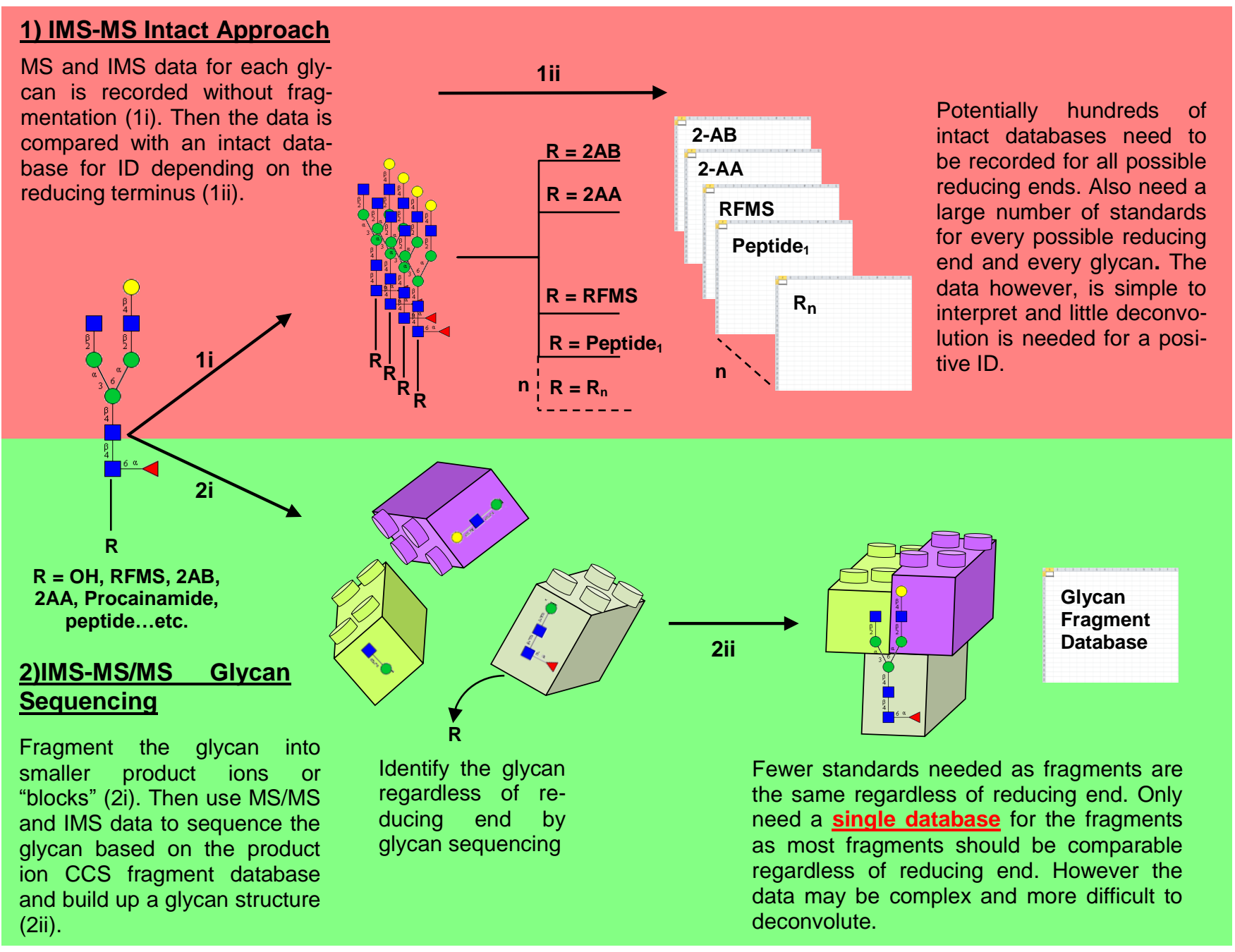

Scheme 1. Comparison of 1) IMS-MS intact analysis and 2) IMS-MS/MS Glycan sequencing analysis approaches to glycan identification.

approach (Scheme 1.1). The intact IMS-MS approach is used without fragmentation, so CCS values of the intact glycans/glycoconjugates are recorded and used to identify the intact glycan. ${ }^{21,22}$ The intact IMS-MS approach is simple to interpret and easy to deconvolute however, it cannot be applied to the same glycan isomer but with a differing reducing end i.e. Rapi-fluor (RFMS) reducing end vs peptide reducing end. In addition, intact IMS-MS CCS values are of little use when trying to identify the structure of new or previously unseen glycans that have limited prior data available and cannot to identified by LC or MS. This makes the intact IMS-MS approach rather limited as several databases are needed to capture all possible CCS values for all possible reducing ends. This becomes impractical especially when considering glycopeptide analysis where the number of potential reducing end peptides becomes extremely large. A UniProt search suggests humans alone have around $\sim 4500$ proteins that are glycosylated. ${ }^{23}$

To alleviate the problem of having to generate thousands of databases several groups have started to move towards a bottom-up fragment based IMS-MS/MS glycan sequencing analysis (Scheme 1.2). ${ }^{16,24-28}$ For this approach the glycans are fragmented prior to IMS analysis to generate unique product ions or "blocks" with unique $\mathrm{m} / \mathrm{z}$ and CCS values. The blocks are then pieced back together to determine the glycan's structure or determine some of the structural motifs that the glycan contains. The carbohydrate blocks generated during fragmentation should be almost identical for each glycan regardless of the reducing terminus attached to the glycan (as long as the fragments don't contain the reducing end) i.e. the Domon-Costello ${ }^{29}$ product ion CCS values from a glycopeptide should match the Domon-Costello ${ }^{29}$ product ion CCS values from RFMS labelled glycan. Therefore, the glycan sequencing approach only requires a single fragment ion database for all glycans, regardless of reducing end. A major drawback of glycan sequencing is the complex nature of the analysis.

LC, IMS and MS can be combined into a single analytical technique for glycan analysis, known as LC-IMS-MS. LC-IMSMS analysis allows for a multi-dimensional analysis, by combining $m / z$, GU and CCS data to improve glycan characterization and can be used for both intact and fragment based glycan sequencing IMS analysis. This has been described by Wongtrakul-Kish et $\mathrm{al}^{30}$, who demonstrated that through exploiting the aforementioned orthogonal attributes for intact glycans (for glycans from glycosphingolipids) that glycan isomer identification can be increased up to $\sim 90 \%$. Whilst this is a promising methodology, substantial improvement to the identification of specific glycan epitopes and isomers is possible by including the attributes of the glycans that can be derived from the fragmentation of the glycans from the same methodology. Such an approach could reduce ambiguity, be applicable across glyco-analytical platforms and lends itself to be an ideal analytical tool for glycan sequencing.

In this study, we investigated the potential of LC-IMS-MS to characterize glycan branching and isomerism through fluorescently labelled released glycan (glycomic) and glycopeptide (glyco- 
proteomic) investigations. Specifically, we inspected the usefulness of both IMS-MS intact and IMS-MS/MS glycan sequencing strategies for identifying isomeric glycans and the methods applicability for cross platform studies (i.e. between glycomic and glycopeptideomics studies). There are to date few active databases available containing glycan IMS information, especially for comprehensive positive ion IMS-MS intact data and IMS-MS/MS glycan sequencing data. ${ }^{31,32}$ Therefore, the data collected is published on an online database to complement the currently few databases containing glycan IMS information.

\section{Results and Discussion}

\section{Differentiating Between RFMS Labelled Glycan Arm Isomers F(6)A2G1 and F(6)A2G1' using CCSDs from IMS-MS Intact Analysis and IMS-MS/MS Glycan Sequencing Analysis.}

Initially we were interested to see if we could obtain IMS data from isomeric $\mathrm{N}$-glycans, and assess whether IMS could be used to identify unique CCS values or features to help identify glycans more accurately for both glycomic and glycoproteimic workflows. We identified that the glycans from Immunoglobulin $G$ (IgG) would be an ideal case study as it typically contains a mixture of two F(6)A2G1 isomers (Figure S1a \& S1b). ${ }^{33}$ These isomers differ by the position of a $\beta 1,4$ galactose on either the $\alpha 1,3$ arm or the $\alpha 1,6$ arm of the glycan (Figure S1). This mixture of isomers was ideal to assess whether glycan isomers could be identified in positive ion mode using IMS.

Glycans were released from a standard IgG biologic sample and labelled with RFMS followed by analysis with UPLC(HILIC)FLR-IMS-MS using a H-Class UPLC coupled to a Synapt G2-Si QToF (Waters Corp). We analyzed the labelled $N$-glycans using an IMS-MS intact approach (Scheme 1.1). The isomers did separate in the LC with the $\mathrm{F}(6) \mathrm{A} 2 \mathrm{G} 1$ isomer eluting first as has been widely reported previously (Figure S2). ${ }^{33}$ The major species observed in the MS for each isomer was the $[\mathrm{M}+2 \mathrm{H}]^{2+}$ species with an $m / z$ 968. The CCS distributions (CCSD) of the $[\mathrm{M}+2 \mathrm{H}]^{2+}$ species for each isomer was calculated and plotted to see if there were any noticeable differences (Figure S3a \& S3b). The shape of

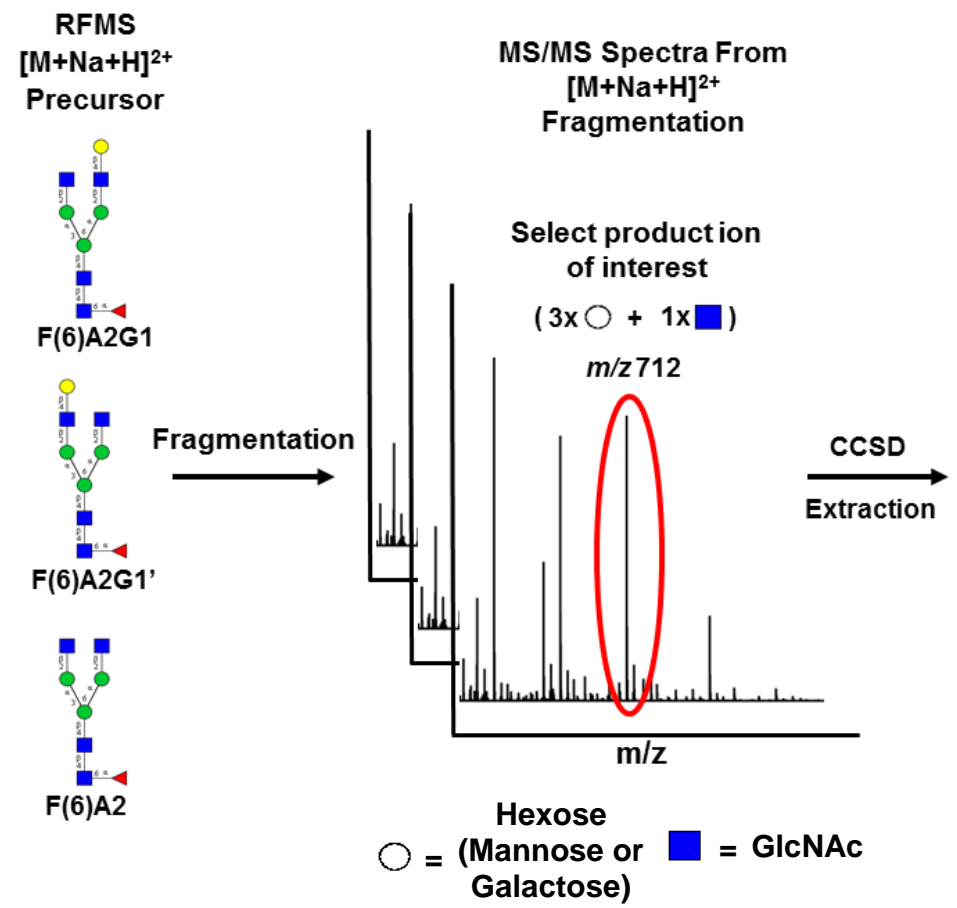

the CCSDs appeared to be different with the $\mathrm{F}(6) \mathrm{A} 2 \mathrm{G} 1$ species having two distinct peaks at $\sim 460 \pm 0.3 \AA$ and $\sim 499 \pm 0.1 \AA$ while the F(6)A2G1' had one clear peak at $\sim 497 \pm 0.3 \AA$ (Figure S3a \& $3 b)$. This demonstrates that a glycans CCSD values can be used to differentiate the glycan isomers

It has been reported in several instances that the presence of alkali adducts can improve separation and identification in the IMS of carbohydrate based molecules. ${ }^{14,34}$ We therefore looked at the most abundant alkali containing species for the $\mathrm{F}(6) \mathrm{A} 2 \mathrm{G} 1$ isomers in the MS, which was the $[\mathrm{M}+\mathrm{H}+\mathrm{Na}]^{2+}$ species. For the $[\mathrm{M}+\mathrm{H}+\mathrm{Na}]^{2+}$ the CCSDs for each glycan isomer were significantly different with peak apexes at $\sim 476 \pm 0.3 \AA$ for $\mathrm{F}(6) \mathrm{A} 2 \mathrm{G} 1$ and $\sim 509 \pm 0.2 \AA$ for F(6)A2G1' (Figure S3c \& 3d). This showed that positive ion mode could be used to resolve these isomers using an intact IMS-MS approach for both $[\mathrm{M}+2 \mathrm{H}]^{2+}$ and $[\mathrm{M}+\mathrm{H}+\mathrm{Na}]^{2+}$ species. Analysis of the alkali metal containing species also provides an additional data point for identification which in turn should help improve ID accuracy. ${ }^{30}$

Although unique CCS values could be determined for the $\mathrm{F}(6) \mathrm{A} 2 \mathrm{G} 1$ isomers using an IMS-MS intact approach, we were interested to see if the glycan sequencing IMS-MS/MS approach could be used to differentiate $\mathrm{F}(6) \mathrm{A} 2 \mathrm{G} 1$ isomers. We released and analyzed the glycans as described previously however this time a voltage was applied in the collision cell during the IMS-MS analysis to generate glycan product ions through fragmentation. Initially we fragmented the $[\mathrm{M}+2 \mathrm{H}]^{2+}$ species at $\mathrm{m} / \mathrm{z} 969$ for each of the isomers. Again here the MS/MS spectra for each glycan isomer were identical making it difficult to differentiate the isomers based on the product ions alone. Furthermore, inspection of the CCSD for each of the Domon-Costello product ions observed was also almost identical between the isomers. For example the CCSD of the Hexose ${ }_{1}$ Hexnac $_{1} \mathrm{~m} / \mathrm{z} 366$ product ion had a peak apex at $\sim 167 \AA$ for both isomers. Some slight differences in CCSD of the Hexose $_{2} \mathrm{HexNAc}_{1} \mathrm{~m} / \mathrm{z}, 528$ product ion were observed however not enough to be diagnostic (results not shown here). Larger glycan fragment structures (more than 4 monosaccharides) were quite weakly observed making CCS values for these larger product ions unreliable or impossible to obtain (Figure S4a).

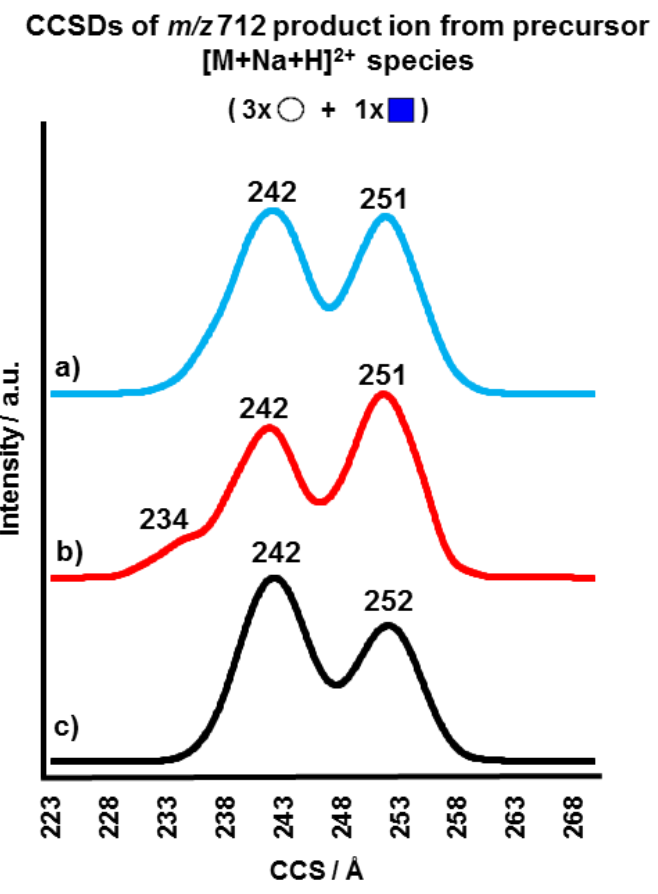

Figure 2. Extraction of CCSDs for the $m / z 712$ product ions. a) CCSD for the $m / z 712$ product ion from fragmentation of $\mathrm{F}(6) \mathrm{A} 2 \mathrm{G} 1 \mathrm{~b}$ ) CCSD for the $m / z, 712$ product ion from fragmentation of $\mathrm{F}(6) \mathrm{A} 2 \mathrm{G} 1$ ' c) CCSD for the $\mathrm{m} / \mathrm{z}, 712$ product ion from fragmentation of $\mathrm{F}(6) \mathrm{A} 2$ 
The sodiated product ions were inspected after fragmenting the $[\mathrm{M}+\mathrm{Na}+\mathrm{H}]^{2+} \mathrm{m} / \mathrm{z} 979$ species for the $\mathrm{F}(6) \mathrm{A} 2 \mathrm{G} 1$ isomers. Fragmenting the sodiated species produced larger sodiated glycan product ions when compared to the $[\mathrm{M}+2 \mathrm{H}]^{2+}$ species, with up to 6-monosacharide product ion fragments being easily observed for the $[\mathrm{M}+\mathrm{H}+\mathrm{Na}]^{2+}$ species (Figure $\mathrm{S} 4 \mathrm{~b}$ ). This phenomena has been previously reported for glycopeptides by R. R. Seipert et al with the sodiated species giving access to different product ions upon fragmentation. ${ }^{35}$ From the sodiated product ions the CCSDs of the $\mathrm{m} / \mathrm{z} 712$ product ion $\left(\mathrm{Hexose}_{3} \mathrm{HexNAc}_{1}\right.$ ) differed most significantly between the two $\mathrm{F}(6) \mathrm{A} 2 \mathrm{G} 1$ isomers, enough so as to be diagnostic (Figure 1a \& 1b). A significant and clear shoulder peak was observed for the CCSD of the $\mathrm{F}(6) \mathrm{A} 2 \mathrm{G} 1, \mathrm{~m} / \mathrm{z} 712$ product ion at $\sim 234 \pm 0.3 \AA$ (Figure 1 b) vs the CCSD of the F(6)A2G1 m/z 712 product ion which had no apparent shoulder peak (Figure 1a). The analysis was carried out in triplicate and the $234 \AA$ shoulder was present in all of the replicates ran for $\mathrm{F}(6) \mathrm{A} 2 \mathrm{G} 1$ ' isomer (Figure S5).

The $m / z 712$ CCSD for each of the F(6)A2G1 isomers contains 2-3 clear observable peaks and/or features (Figure 1a \& 1b). This is most likely because there are several different product ion isomers of Hexose $\mathrm{HexNAc}_{3}$ that could produce the CCSD for the $\mathrm{m} / z 712$ product ion (Table S1 \& S2). As a result multiple peaks are observed for a single product ion in the CCSD for the $\mathrm{m} / z, 712$ product ion. This makes identifying the cause of the difference in CCSDs between the $m / z, 712$ product ions from $\mathrm{F}(6) \mathrm{A} 2 \mathrm{G} 1$ and $\mathrm{F}(6) \mathrm{A} 2 \mathrm{G1}$ ' somewhat challenging. However, from the glycan structures it is likely the main differences observed in the CCSDs is due to the presence of a Gal- $\beta 1,4-G l c N A c-\beta 1,2-M a n-\alpha 1,6-M a n$ $\mathrm{B}_{4} \mathrm{Y}_{3} / \mathrm{C}_{4} / \mathrm{Z}_{3}$ product ion for $\mathrm{F}(6) \mathrm{A} 2 \mathrm{G} 1$ vs Gal- $\beta 1,4-\mathrm{GlcNAc}-\beta 1,2-$ Man- $\alpha 1,3-$ Man $\mathrm{B}_{4} \mathrm{Y}_{3} / \mathrm{C}_{4} / \mathrm{Z}_{3}$ product ion for $\mathrm{F}(6) \mathrm{A} 2 \mathrm{G} 1$ (Table $\mathrm{S} 1$ : (c), (g) \& Table S2: (c), (g)). In order to see if this is the likely cause for the difference between F(6)A2G1 and F(6)A2G1' $\mathrm{m} / \mathrm{z}$ 712 product ion CCSDs we decided to do a subtraction analysis.

The $\mathrm{F}(6) \mathrm{A} 2$ glycan is also observed in IgG and differs in structure to both $\mathrm{F}(6) \mathrm{A} 2 \mathrm{G} 1$ and $\mathrm{F}(6) \mathrm{A} 2 \mathrm{G} 1$ ' due to the absence of terminal galactose (Figure S1c). The product ion analysis of the $[\mathrm{M}+\mathrm{Na}+\mathrm{H}]^{2+}$ species of the $\mathrm{F}(6) \mathrm{A} 2$ glycan was found to also contain a $\mathrm{m} / \mathrm{z} 712$ product ion despite not containing any terminal galactose.. Therefore, the CCSD of the $\mathrm{m} / z, 712$ product ion from $\mathrm{F}(6) \mathrm{A} 2$ (Figure 1c) can be used to perform a subtraction analysis as none of the product ions pertain to the $\mathrm{B}_{4} \mathrm{Y}_{3} / \mathrm{C}_{4} / \mathrm{Z}_{3}$ fragment for Gal- $\beta 1,4-G l c N A c-\beta 1,2-M a n-\alpha 1,3 / 6-M a n$. Therefore subtraction

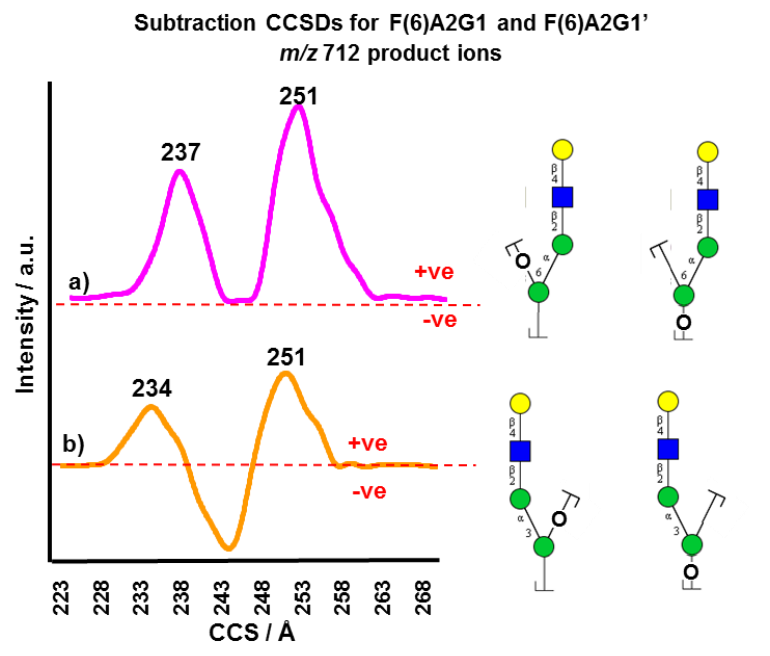

Figure 2. Subtraction CCSDs for $m / z 712$ product ions a) $\mathrm{F}(6) \mathrm{A} 2 \mathrm{G} 1 \mathrm{~b}) \mathrm{F}(6) \mathrm{A} 2 \mathrm{G} 1$ ' following removal of CCSD $\mathrm{m} / \mathrm{z}$ 712 product ion signal from $\mathrm{F}(6) \mathrm{A} 2$ of the $\mathrm{F}(6) \mathrm{A} 2 \mathrm{~m} / z, 712 \mathrm{CCSD}$ from CCSD of $\mathrm{F}(6) \mathrm{A} 2 \mathrm{G} 1$ and $\mathrm{F}(6) \mathrm{A} 2 \mathrm{G} 1^{\prime} \mathrm{m} / \mathrm{z} 712$ CCSDs should leave mostly CCSD signal from the Gal- $\beta 1,4-G l c N A c-\beta 1,2-M a n-\alpha 1,3 / 6-M_{a n} B_{4} Y_{3} / C_{4} / Z_{3} m / z$ 712 product ions. Therefore we subtracted the $\mathrm{F}(6) \mathrm{A} 2 \mathrm{CCSD}$ for the $\mathrm{m} / \mathrm{z}, 712$ product ion from the $\mathrm{F}(6) \mathrm{A} 2 \mathrm{G} 1$ and $\mathrm{F}(6) \mathrm{A} 2 \mathrm{G} 1$, CCSDs (Figure 2). This revealed that there was indeed a true shoulder peak at $\sim 234 \pm 0.15 \AA$ for the $\mathrm{F}(6) \mathrm{A} 2 \mathrm{G} 1{ }^{\prime} \mathrm{m} / \mathrm{z} 712$ product ion CCSD (Figure 2b) suggesting the shoulder peak in Figure $1 \mathrm{~b}$ is due to the presence of signal in the CCSD from Gal- $\beta 1,4-$ GlcNAc- $\beta 1,2-$ Man- $\alpha 1,3-$ Man $\mathrm{B}_{4} \mathrm{Y}_{3} / \mathrm{C}_{4} / \mathrm{Z}_{3} \mathrm{~m} / \mathrm{z} 712$ product ions. Interestingly during the subtraction a peak at $\sim 237 \pm 0.1 \AA$ for $\mathrm{F}(6) \mathrm{A} 2 \mathrm{G} 1$ isomer was also observed (Figure 2a). This F(6)A2G1 CCSD peak at $\sim 237 \AA$ suggests that the underlying signal is probably from Gal- $\beta 1,4-G l c N A c-\beta 1,2-M a n-\alpha 1,6-M a n B_{4} \mathrm{Y}_{3} / \mathrm{C}_{4} / \mathrm{Z}_{3} \mathrm{~m} / z$ 712 product ions contributing to the CCSD. A peak at $\sim 251 \AA$ was also observed in the subtractions of both $\mathrm{F}(6) \mathrm{A} 2 \mathrm{G} 1$ and $\mathrm{F}(6) \mathrm{A} 2 \mathrm{G} 1$ ' but, as it was present in both subtractions it could not be used as a diagnostic feature to differentiate $\mathrm{F}(6) \mathrm{A} 2 \mathrm{G} 1$ from F(6)A2G1'.

This now gave us the $\mathrm{m} / z 712$ diagnostic product ion CCSD features to look for to perform glycan sequencing in order to distinguish between $\mathrm{F}(6) \mathrm{A} 2 \mathrm{G} 1$ and $\mathrm{F}(6) \mathrm{A} 2 \mathrm{G} 1$ '. Therefore we were interested to see if we could use these diagnostic product ion CCSDs to identify F(6)A2G1 and F(6)A2G1' on a glycopeptide.

\section{Glycopeptide Analysis Using IMS-MS Intact Analysis and IMS-MS/MS Glycan Sequencing can Differenti- ate Between Glycan Arm Isomers F(6)A2G1 and F(6)A2G1'.}

We prepared the $\mathrm{F}(6) \mathrm{A} 2 \mathrm{G} 1$ and $\mathrm{F}(6) \mathrm{A} 2 \mathrm{G} 1$ ' glycopeptides by digesting a standard IgG biologic with trypsin. The tryptic glycopeptides resulting from the digestion were analyzed using the same UPLC(HILIC)-FLR-IMS-MS as the glycomic analysis with one slight exception; the glycopeptides were separated with a 300 $\AA$ glycoprotein HILIC column (Waters Corp.) separating the different glycopeptide isomers prior to IMS-MS analysis. Glycopeptides were identified based on RT and $\mathrm{m} / \mathrm{z}$ (based on the peptide of the glycopeptide consisting of EEQYNSTYR amino acids). The $300 \AA$ HILIC glycoprotein column was able to easily separate the EEQYN-[F(6)A2G1]-STYR and EEQYN-[F(6)A2G1']-STYR glycopeptides allowing for simple analysis with no risk of the isomers co-eluting and complicating the CCSD analysis (Figure S6). We initially carried out intact IMS-MS analysis on the $\mathrm{F}(6) \mathrm{A} 2 \mathrm{G} 1$ and $\mathrm{F}(6) \mathrm{A} 2 \mathrm{G} 1$ ' containing glycopeptides. The $\mathrm{m} / \mathrm{z}$ $1399[\mathrm{M}+2 \mathrm{H}]^{2+}$ species for the $\mathrm{F}(6) \mathrm{A} 2 \mathrm{G} 1$ glycopeptide had a CCSD peak apex at $\sim 537 \pm 1.4 \AA$ for intact IMS-MS analysis while the $\mathrm{F}(6) \mathrm{A} 2 \mathrm{G} 1$ ' had a CCSD peak apex at $\sim 537 \pm 0.7 \AA$ (Figure S7a and S7b). The $\mathrm{m} / \mathrm{z} 1410[\mathrm{M}+\mathrm{Na}+\mathrm{H}]^{2+}$ species for the F(6)A2G1 glycopeptide had a CCSD peak apex at $\sim 537 \pm 1.5 \AA$ for intact IMS-MS analysis while the F(6)A2G1' had a CCSD peak apex at $\sim 544 \pm 0.7 \AA$ (Figure S7c and S7d). The m/z 933 $[\mathrm{M}+3 \mathrm{H}]^{3+}$ species for the $\mathrm{F}(6) \mathrm{A} 2 \mathrm{G} 1$ glycopeptide had CCSD peak apexes at $\sim 589 \pm 1.1 \AA$ and $\sim 655 \pm 0.9 \AA$ for intact IMS-MS analysis while the $\mathrm{F}(6) \mathrm{A} 2 \mathrm{G} 1$ ' had CCSD peak apexes at $\sim 592 \pm 1.3 \AA$ and $\sim 678 \pm 1.2 \AA$ (Figure S7e and S7f). As expected (due to differing reducing terminuses) none of the intact glycopeptide CCSDs matched that observed for intact analysis of the RFMS labelled glycans, highlighting how intact IMS-MS approach cannot be used across platforms i.e. between glycans with differing reducing ends such as RFMS and peptides.

We carried out IMS-MS/MS glycan sequencing on the $[\mathrm{M}+\mathrm{Na}+\mathrm{H}]^{2+}$ glycopeptide species $(\mathrm{m} / \mathrm{z}, 1410)$ for both $\mathrm{F}(6) \mathrm{A} 2 \mathrm{G} 1$ and $\mathrm{F}(6) \mathrm{A} 2 \mathrm{G} 1$ ' IgG glycopeptide isomers. As expected we saw similar fragments for the glycopeptide in the mass spectra as observed for the released glycans including the diagnostic $\mathrm{m} / \mathrm{z} 712$ product ion. Both the $\mathrm{F}(6) \mathrm{A} 2 \mathrm{G} 1$ glycopeptide and $\mathrm{F}(6) \mathrm{A} 2 \mathrm{G} 1$, 
glycopeptides gave very similar CCSDs for the $\mathrm{m} / \mathrm{z}, 712$ product ion when compared to the CCSDs from the same RFMS labelled glycan (Figure 1 vs S8 \& S9). Again a clear shoulder peak observed at $\sim 234 \pm 0.2 \AA$ for the F(6)A2G1' glycopeptide was the most distinguishing feature between the CCSDs allowing us to distinguish the glycan isomers present on the glycopeptides (Figure S8 \& S9). The standard error of the mean (SEM) for the glycopeptide glycan sequencing data was slightly higher than of the released glycans suggesting the glycopeptide IMS-MS/MS data is slightly more variable than the RFMS results. This is probably due to the weaker intensity of glycopeptide product ions for glycopeptide data compared to RFMS labelled glycans. Despite this the glycopeptide CCS data observed for the F(6)A2G1 isomers is still well within the $1.5 \%$ error of the instrument stated by the manufacturer.

These results highlight the ubiquitous nature of the CCSDs of product ions from IMS-MS/MS glycan sequencing from different glycan analytics; in this case glycomics vs glycoproteomics. One can use the same fragments as diagnostic features in both analytics. In contrast, these results also highlight the futility of intact IMS-MS approach to differentiate the same glycan isomers from glyco-conjugates with differing substitutions at a glycans reducing termini, i.e. intact IMS-MS glycomic data cannot be used to help identify isomers in intact IMS-MS glycoproteomic data.

CCSDs from IMS-MS Intact Analysis and IMSMS/MS Glycan Sequencing can Differentiate Sialic Acid Position of RFMS Labelled Glycan Arm Isomers F(6)A2G1S1 and F(6)A2G1'S1.

Further investigations were made to determine whether the nature of branching of $\mathrm{F}(6) \mathrm{A} 2 \mathrm{G} 1 \mathrm{~S} 1$ isomers could be differentiated using IMS-MS intact and IMS-MS/MS glycan sequencing approaches. $\mathrm{F}(6) \mathrm{A} 2 \mathrm{G} 1 \mathrm{~S} 1$ and $\mathrm{F}(6) \mathrm{A} 2 \mathrm{G} 1$ 'S $\mathrm{S}$ are similar in structure to the $\mathrm{F}(6) \mathrm{A} 2 \mathrm{G} 1$ and $\mathrm{F}(6) \mathrm{A} 2 \mathrm{G} 1$ ' glycans; i.e. isomers differ by the substitution of a $\beta 1,4$ galactose- $\alpha 2,3 \mathrm{~N}$-acetylneuraminic acid on either the $\alpha 1,3$ arm or the $\alpha 1,6$ arm of the glycan (Figure $\mathrm{S} 10$ ). In this experiment glycans from $\alpha$-1-antitrypsin (AAT) recombinantly produced in Chinese hamster ovary cells (CHO) were released and labelled with RFMS. It is known that AAT produced in $\mathrm{CHO}$ contains a range of sialylated and branched $\mathrm{N}$ glycans including a mixture of both F(6)A2G1S1 and F(6)A2G1'S1 (Figure S11). ${ }^{36}$ Furthermore, it is worth noting that as the AAT analyzed was produced in $\mathrm{CHO}$ that all glycan structures that contain sialic acids described here are those with $\alpha 2,3$ linkage unless otherwise stated. The intact IMS-MS analysis of RFMS released and labelled glycans F(6)A2G1S1 and F(6)A2G1'S1 showed a difference in the CCSDs between the two isomers for $m / z 1115[\mathrm{M}+2 \mathrm{H}]^{2+}$ with $\mathrm{F}(6) \mathrm{A} 2 \mathrm{G} 1 \mathrm{~S} 1$ having a CCSD peak apex at $\sim 510 \pm 0.1 \AA$ while the CCSD of F(6)A2G1'S1 had peak apexes at $\sim 494 \pm 0.1 \AA$ and $\sim 514 \pm 0.2 \AA$ (Figure S12a \& S12b). Intact IMS-MS analysis of the $\mathrm{m} / \mathrm{z} 1126$ $[\mathrm{M}+\mathrm{Na}+\mathrm{H}]^{2+}$ species showed that the $\mathrm{F}(6) \mathrm{A} 2 \mathrm{G} 1 \mathrm{~S} 1$ isomer had CCSD peak apexes at $\sim 498 \pm 0.2 \AA$ and $522 \pm 0.1 \AA$ whereas the F(6)A2G1'S1 isomer had a peak apex at $542 \pm 0.3 \AA$ (Figure S12c \& $\mathrm{S} 12 \mathrm{~d})$.

We also performed glycan sequencing IMS-MS/MS on the $\mathrm{F}(6) \mathrm{A} 2 \mathrm{G} 1 \mathrm{~S} 1$ and $\mathrm{F}(6) \mathrm{A} 2 \mathrm{G} 1$ 'S1 isomers on both $[\mathrm{M}+2 \mathrm{H}]^{2+}$ \& $[\mathrm{M}+\mathrm{Na}+\mathrm{H}]^{2+}$ species. From the glycan sequencing analysis the most distinguishing CCSDs between the two isomers was again the $m / z, 712$ product ion observed when fragmenting the $[\mathrm{M}+\mathrm{Na}+\mathrm{H}]^{2+}$ species. The differences observed for the $\mathrm{m} / \mathrm{z}, 712$ CCSDs ions for F(6)A2G1S1 (Figure S13) and F(6)A2G1'S1 (Figure S14) were very similar to those observed for the $\mathrm{F}(6) \mathrm{A} 2 \mathrm{G} 1$ isomers described earlier, with a shoulder peak apparent at around $\sim 234 \pm 0.3 \AA$ for F(6)A2G1'S1 (Figure S14). This allows us to differentiate between the F(6)A2G1S1 and
$\mathrm{F}(6) \mathrm{A} 2 \mathrm{G} 1$ 'S1 isomers using the glycan sequencing approach. We did not see any interesting product ions that contained sialic acid that could be used for isomer differentiation. This is likely due to the labile nature of sialic acid. Unfortunately we were unable to obtain enough of either F(6)A2G1S1 or F(6)A2G1'S1 glycans on a glycopeptide to attempt glycan sequencing on a glycopeptide.

Differentiating RFMS Labelled Glycan Positional Isomers $\mathrm{F}(6) A 3$ and $F(6) A 2 B$ using IMS-MS Intact Analysis and IMS-MS/MS Glycan Sequencing.

An investigation into whether intact IMS-MS analysis and IMS-MS/MS glycan sequencing would be beneficial in helping to differentiate positional glycan isomers. Namely we were interested in the tri-antennary $\mathrm{F}(6) \mathrm{A} 3$ and bisecting $\mathrm{F}(6) \mathrm{A} 2 \mathrm{~B}$ glycans (Figure S15). These structures differ in the position of a single terminal GlcNAc residue. For example F(6)A3 contains 3 terminal GlcNAc residues with typically two GlcNAc residues on the $\alpha 1,6$ mannose of the glycan and one on the $\alpha 1,3$ mannose (Figure $\mathrm{S} 15 \mathrm{a})$. For $\mathrm{F}(6) \mathrm{A} 2 \mathrm{~B}$ one GlcNAc residue can be found on the $\alpha 1,6$ mannose of the glycan and one on the $\alpha 1,3$ mannose with the third terminal GlcNAc being found on the core mannose which is typically referred to as the bisecting GlcNAc (Figure S15b). In traditional positive ion MS these structures are difficult to distinguish and give very similar MS/MS spectra. Both these structures were found in the CHO AAT but we also analyzed two IgG molecules expressed in $\mathrm{CHO}$ cells which through modulation of their glycosyltransferases express different glycan isomers. Therefore IgG samples where F(6)A3 was not expressed and another IgG sample where the $\mathrm{F}(6) \mathrm{A} 2 \mathrm{~B}$ was not expressed were used (See SI for more information on the IgG production method). The RFMS released and labelled $\mathrm{F}(6) \mathrm{A} 2 \mathrm{~B}$ and $\mathrm{F}(6) \mathrm{A} 3$ isomers separated well on the HILIC column with the $\mathrm{F}(6) \mathrm{A} 2 \mathrm{~B}$ eluting prior to the $\mathrm{F}(6) \mathrm{A} 3$, therefore there was no risk of co-elution complicating CCS analysis.

Intact IMS-MS of the released RFMS F(6)A3 and F(6)A2B glycans gave different CCSDs for $m / z, 989[\mathrm{M}+2 \mathrm{H}]^{2+}$ with $\mathrm{F}(6) \mathrm{A} 3$

CCSD's of $m / z 712$ product ion from precursor

$[\mathrm{M}+\mathrm{Na}+\mathrm{H}]^{2+}$ species for $\mathrm{F}(6) \mathrm{A} 3$ and $\mathrm{F}(6) \mathrm{A} 2 \mathrm{~B}$

$$
(3 x O+1 x \square)
$$

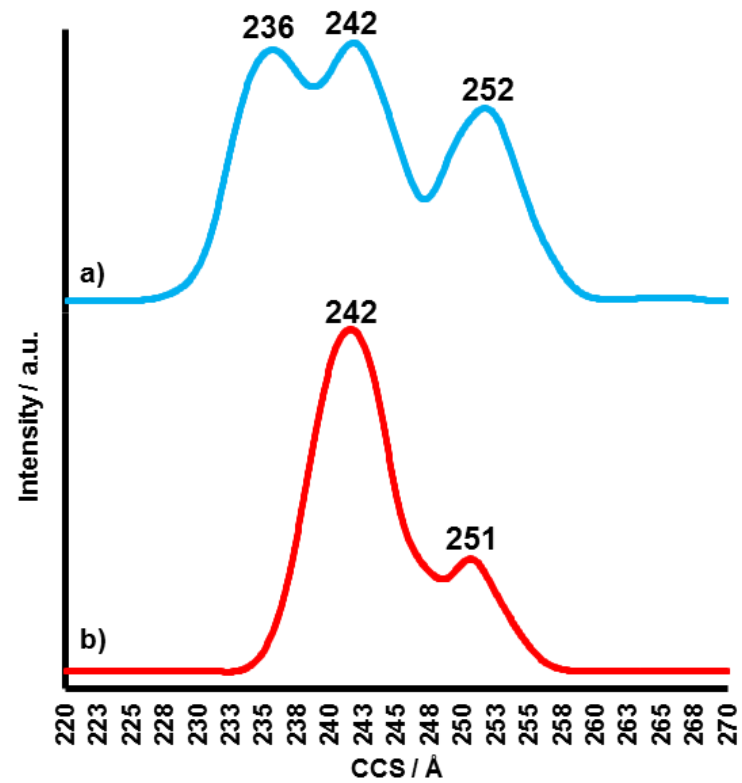

Figure 3. CCSDs for the $m / z, 712$ product ions. a) CCSD for the $\mathrm{m} / \mathrm{z} 712$ product ion from fragmentation of $\mathrm{F}(6) \mathrm{A} 3 \mathrm{~b}$ ) CCSD for the $m / z, 712$ product ion from fragmentation of $\mathrm{F}(6) \mathrm{A} 2 \mathrm{~B}$ '. 
having CCSD peak apexes at $\sim 483 \pm 0.1 \AA$ and $\sim 508 \pm 0.1 \AA$ while $\mathrm{F}(6) \mathrm{A} 2 \mathrm{~B}$ had CCSD peak apexes at $450 \pm 0.6 \AA$, $474 \pm 0.3$ $\AA$ and $505 \pm 0.2 \AA$ (Figure S16a \& S16b). The $\mathrm{m} / \mathrm{z} 1000$ $[\mathrm{M}+\mathrm{Na}+\mathrm{H}]^{2+}$ species had a CCSD peak apex at $520 \pm 0.1 \AA$ for $\mathrm{F}(6) \mathrm{A} 3$ isomer while $\mathrm{F}(6) \mathrm{A} 2 \mathrm{~B}$ CCSD had a peak apex at $510 \pm$ $0.1 \AA$ (Figure S16c \& S16d). This allowed for isomer identification using IMS-MS intact approach.

The glycan sequencing approach also produced some unique product ions in the CCSDs which were distinct for $\mathrm{F}(6) \mathrm{A} 3$ and $\mathrm{F}(6) \mathrm{A} 2 \mathrm{~B}$ isomers. Again the most striking of these was the CCSD for the $m / z 712$ product ion observed during IMS-MS/MS for both the $\mathrm{F}(6) \mathrm{A} 3$ and $\mathrm{F}(6) \mathrm{A} 2 \mathrm{~B}[\mathrm{M}+\mathrm{Na}+\mathrm{H}]^{2+}$ species. The $\mathrm{F}(6) \mathrm{A} 3$ CCSD for the $m / z, 712$ product ion produced a CCSD containing three peaks at $\sim 236 \pm 0.1 \AA, \sim 242 \pm 0.3 \AA$ and $\sim 252 \pm 0.1 \AA$ (Figure $3 \mathrm{a}$ ). In contrast the CCSD of the $\mathrm{m} / \mathrm{z} 712$ product ion from $\mathrm{F}(6) \mathrm{A} 2 \mathrm{~B}$ contained two peaks at $\sim 242 \pm 0.1 \AA \& \sim 251 \pm 0.4 \AA$ (Figure $3 b$ ). This may be due to F(6)A2B's bisecting GlcNAc affecting the formation of the $m / z, 712$ product ions during fragmentation as the additional bisecting bond needs to be broken to form the same $m / z, 712$ product ions in $\mathrm{F}(6) \mathrm{A} 2 \mathrm{~B}$ in contrast to the $\mathrm{F}(6) \mathrm{A} 3$ structure although, further analysis is required to prove this hypothesis. Without CCSD subtraction analysis it is clear that the $\sim 236 \AA$ observed for the $\mathrm{F}(6) \mathrm{A} 3 \mathrm{~m} / \mathrm{z} 712 \mathrm{CCD}$ is distinct from $\mathrm{F}(6) \mathrm{A} 2$ (Figure 1c vs Figure $3 \mathrm{a}$ ) suggesting that the $\sim 236 \AA$ peak could be attributed to the additional $\beta 1,4$ GlcNAc containing fragments. It is less clear for the F(6)A2B glycan with the $\sim 241 \AA$ peak being much more intense in the $\mathrm{m} / \mathrm{z}, 712$ CCSD when compared to $\mathrm{F}(6) \mathrm{A} 2$, suggesting that the bisecting GlcNAc may be attributed to its increase in signal although it is difficult to confirm (Figure 1c vs Figure 3b).

Other product ion CCSDs observed during IMS-MS/MS glycan sequencing from $\mathrm{F}(6) \mathrm{A} 2 \mathrm{~B}$ and $\mathrm{F}(6) \mathrm{A} 3$ were also significantly different that they can be termed diagnostic. For example the CCSD observed for the $m / z 550$ product ion $\left(\right.$ Hexose $_{2} \mathrm{HexNAc}_{1}$ ) for $\mathrm{F}(6) \mathrm{A} 2 \mathrm{~B}$ contained two clear peaks at $\sim 214 \pm 0.2 \AA$ and $\sim 223$ $\pm 0.1 \AA$ while the $\mathrm{F}(6) \mathrm{A} 3$ contained only a single peak at $\sim 215 \pm$ $0.1 \AA$ (Figure S17). In addition the CCSD observed for the $\mathrm{m} / \mathrm{z}$ 915 product ions $\left(\mathrm{Hexose}_{3} \mathrm{HexNAc}_{2}\right.$ ) for $\mathrm{F}(6) \mathrm{A} 2 \mathrm{~B}$ contained one clear peak at $\sim 275 \pm 0.1 \AA$ while the CCSD of F(6)A3 m/z, 915 product ion contained two peaks at $\sim 275 \pm 0.1 \AA$ and $\sim 286 \pm 0.2$ $\AA$ (Figure S18). These features were consistent between both RFMS glycans released from AAT and those from the IgG samples.

\section{Glycopeptide Analysis Using CCSDs from IMS-MS Intact Analysis and IMS-MS/MS Glycan Sequencing can Differentiate Glycan Positional Isomers F(6)A3 and $F(6) A 2 B$.}

Further investigation was carried out into the power of diagnostic product ions and their associated CCSDs described above to differentiate $\mathrm{F}(6) \mathrm{A} 2 \mathrm{~B}$ and $\mathrm{F}(6) \mathrm{A} 3$ on glycopeptides. This was performed on glycopeptides derived from the glycosyltransferase modulated $\mathrm{IgG}$ samples bearing $\mathrm{F}(6) \mathrm{A} 3$ and $\mathrm{F}(6) \mathrm{A} 2 \mathrm{~B}$ after tryptic digestion. We initially performed intact IMS-MS analysis on the IgG glycopeptides containing $\mathrm{F}(6) \mathrm{A} 2 \mathrm{~B}$ and $\mathrm{F}(6) \mathrm{A} 3$ glycans using the same glycopeptide analysis method described earlier. Only slight differences were observed in the CCSDs between the glycopeptides isomers for the $m / z, 1419[\mathrm{M}+2 \mathrm{H}]^{2+}$ species with F(6)A3 CCSD having a peak apex at $549 \pm 0.3 \AA$ while the $\mathrm{F}(6) \mathrm{A} 2 \mathrm{~B}$ had a CCSD peak apex at $548 \pm 0.6 \AA$ (Figure S19a \& Figure $\mathrm{S} 19 \mathrm{~b})$. The $\mathrm{m} / \mathrm{z} 1430[\mathrm{M}+\mathrm{Na}+\mathrm{H}]^{2+}$ species also showed only slight differences between the isomers with $\mathrm{F}(6) \mathrm{A} 3$ having a peak apex at $558 \pm 0.2 \AA$ whereas $\mathrm{F}(6) \mathrm{A} 2 \mathrm{~B}$ had a CCSD peak apex at $557 \pm 0.4 \AA$ (Figure S19c \& S19d). The $\mathrm{m} / \mathrm{z} 946$ $[\mathrm{M}+3 \mathrm{H}]^{3+}$ species was the most diagnostic species observed during the intact IMS-MS analysis with the $\mathrm{F}(6) \mathrm{A} 3$ having CCSD peak apexes at $598 \pm 2.0 \AA$ and $647 \pm 3.4 \AA$ while $\mathrm{F}(6) \mathrm{A} 2 \mathrm{~B}$ CCSD had a single peak apex at $620 \pm 1.0 \AA$ (Figure S19e \& $\mathrm{S} 19 \mathrm{f})$. The $\mathrm{m} / z, 937[\mathrm{M}+3 \mathrm{H}]^{3+} \mathrm{CCSDs}$ therefore allowed for differentiation of the glycopeptide isomers.

IMS-MS/MS glycan sequencing was performed on the sodiated glycopeptide species $\left([\mathrm{M}+\mathrm{Na}+\mathrm{H}]^{2+}\right)$ to see if we could observe similar CCSDs for the diagnostic $\mathrm{m} / \mathrm{z}, 550,712$ and 915 product ions as observed for the RFMS released glycans of $\mathrm{F}(6) \mathrm{A} 2 \mathrm{~B}$ and $\mathrm{F}(6) \mathrm{A} 3$. The diagnostic $m / z, 712$ product ion CCSD for the $\mathrm{F}(6) \mathrm{A} 3$ containing glycopeptide contained 3 peaks at $\sim 235 \pm 0.7 \AA$ A, $\sim 241$ $\pm 0.5 \AA$ and $\sim 251 \pm 0.9 \AA$ (Figure S20) similar to that which was seen for the RFMS released F(6)A3 glycan described previously. While the CCSD of for $\mathrm{F}(6) \mathrm{A} 2 \mathrm{~B}$ containing glycopeptide contained 2 peaks at $\sim 241 \pm 1.5 \AA \& \sim 250 \pm 0.9 \AA$ (Figure S21), also similar to what was observed for the released $\mathrm{F}(6) \mathrm{A} 2 \mathrm{~B}$ glycan. In addition CCSDs for the $\mathrm{m} / z, 550$ product ion for $\mathrm{F}(6) \mathrm{A} 3$ had one peak at $\sim 217 \pm 0.8 \AA$ compared to two peaks at $\sim 215 \pm 0.9 \AA$ and $\sim 222 \pm 1.3 \AA$ for the $\mathrm{F}(6) \mathrm{A} 2 \mathrm{~B}$ containing glycopeptide (Figure $\mathrm{S} 22$ ). The $\mathrm{m} / \mathrm{z} 915$ product ion CCSDs from the glycopeptides also showed similar differences as detected for RFMS glycans with the $\mathrm{F}(6) \mathrm{A} 2 \mathrm{~B}$ CCSD for $\mathrm{m} / \mathrm{z} 915$ product ion having a single peak at $\sim 273 \pm 1.2 \AA$ compared to the F(6)A3 CCSD which had two peaks at $\sim 272 \pm 1.5 \AA$ and $\sim 282 \pm 2 \AA$ (Figure S23).

This further cements the notion that the glycan sequencing approach can be used to cross over from released glycans to glycopeptides or any other reducing termini. It is worth noting that the signal of the product ions from the IMS-MS/MS analysis of the $\mathrm{F}(6) \mathrm{A} 3$ and $\mathrm{F}(6) \mathrm{A} 2 \mathrm{~B}$ glycopeptides again was much weaker than that of the released RFMS glycans. This was reflected in the SEM values of the CCSD peaks ranging from \pm 0.5 to \pm 2 . This highlights that the much weaker intensity of glycan product ions observed for glycopeptides may make glycan sequencing of glycopeptides more difficult in comparison to released glycans.

\section{Differentiating Unknown AAT Glycan Isomers Using IMS-MS Intact Analysis and IMS-MS/MS Glycan Sequencing Analysis.}

The final isomers we were interested in analyzing were the $\mathrm{F}(6) \mathrm{A} 2 \mathrm{BG} 1$ isomers and $\mathrm{F}(6) \mathrm{A} 3 \mathrm{G} 1$ isomers. These isomers are identical to the $\mathrm{F}(6) \mathrm{A} 2 \mathrm{~B}$ and $\mathrm{F}(6) \mathrm{A} 3$ glycans, except that they contain an additional terminal $\beta 1$,4-galactose on one of the GlcNAcs (Figure 4a-4f). Theoretically there is a potential total of six isomers all with the same mass, three isomers of the F(6)A2BG1 type (Figure $4 \mathrm{a}-4 \mathrm{c}$ ) and three of the F(6)A3G1 type (Figure 4d4f). CHO AAT was shown to contain up to four of these isomers during RFMS release and intact IMS-MS analysis (Figure S24). We observed this by performing an extracted ion chromatogram at $\mathrm{m} / \mathrm{z} 1070\left(\mathrm{~m} / \mathrm{z}, 1070\right.$ being the $\mathrm{m} / \mathrm{z}$ of $[\mathrm{M}+2 \mathrm{H}]^{2+}$ species of both the $\mathrm{F}(6) \mathrm{A} 2 \mathrm{BG} 1$ and F(6)A3G1 RFMS released glycans) which revealed four clear peaks (Figure S24). Unlike the other structures discussed previously it was not clear which of the four peaks belonged to which isomer of $\mathrm{F}(6) \mathrm{A} 2 \mathrm{BG} 1$ and $\mathrm{F}(6) \mathrm{A} 3 \mathrm{G} 1$, with little information in the literature to help assign the peaks based on RT. For the purpose of this study we therefore named the four potential isomers 1, 2, 3 and 4 based on the order in which they eluted on the HILIC column (Figure S24).

We initially performed intact IMS-MS analysis on the four observed peaks. The $[\mathrm{M}+2 \mathrm{H}]^{2+} \mathrm{m} / \mathrm{z}, 1070$ and $[\mathrm{M}+\mathrm{H}+\mathrm{Na}]^{2+} \mathrm{m} / \mathrm{z} 1081$ species each gave a unique CCSD for both the $[\mathrm{M}+2 \mathrm{H}]^{2+}$ and $[\mathrm{M}+\mathrm{Na}+\mathrm{H}]^{2+}$ species although none of these CCSDs gave any insight into the which potential isomers 1,2, 3 and 4 belonged to (Figure S25).

We then performed IMS-MS/MS glycan sequencing approach on the four isomers with a particular interest in the $[\mathrm{M}+\mathrm{Na}+\mathrm{H}]^{2+}$ species and the $m / z, 712$ product ion discussed previously. The 
Potential F(6)A3G1 and F(6)A2BG1 Isomers.

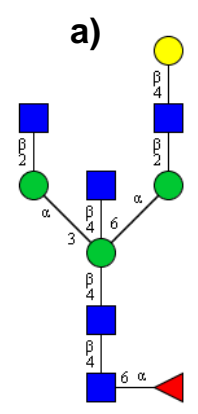

d)

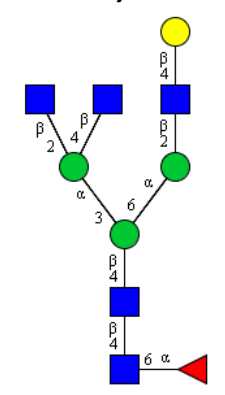

b)

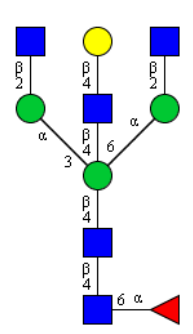

e)

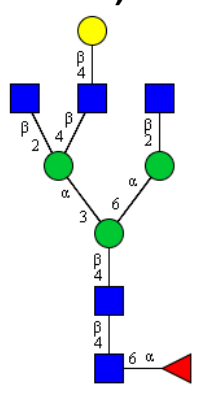

c)

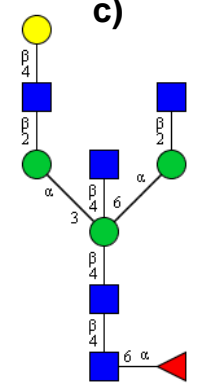

f)

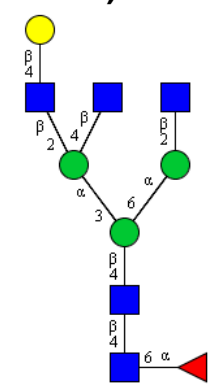

CCSDs of $m / z 712$ product ion from precursor $[\mathrm{M}+\mathrm{Na}+\mathrm{H}]^{2+}$ species from $1,2,3$ and 4 $(3 x \bigcirc+1 x \square)$
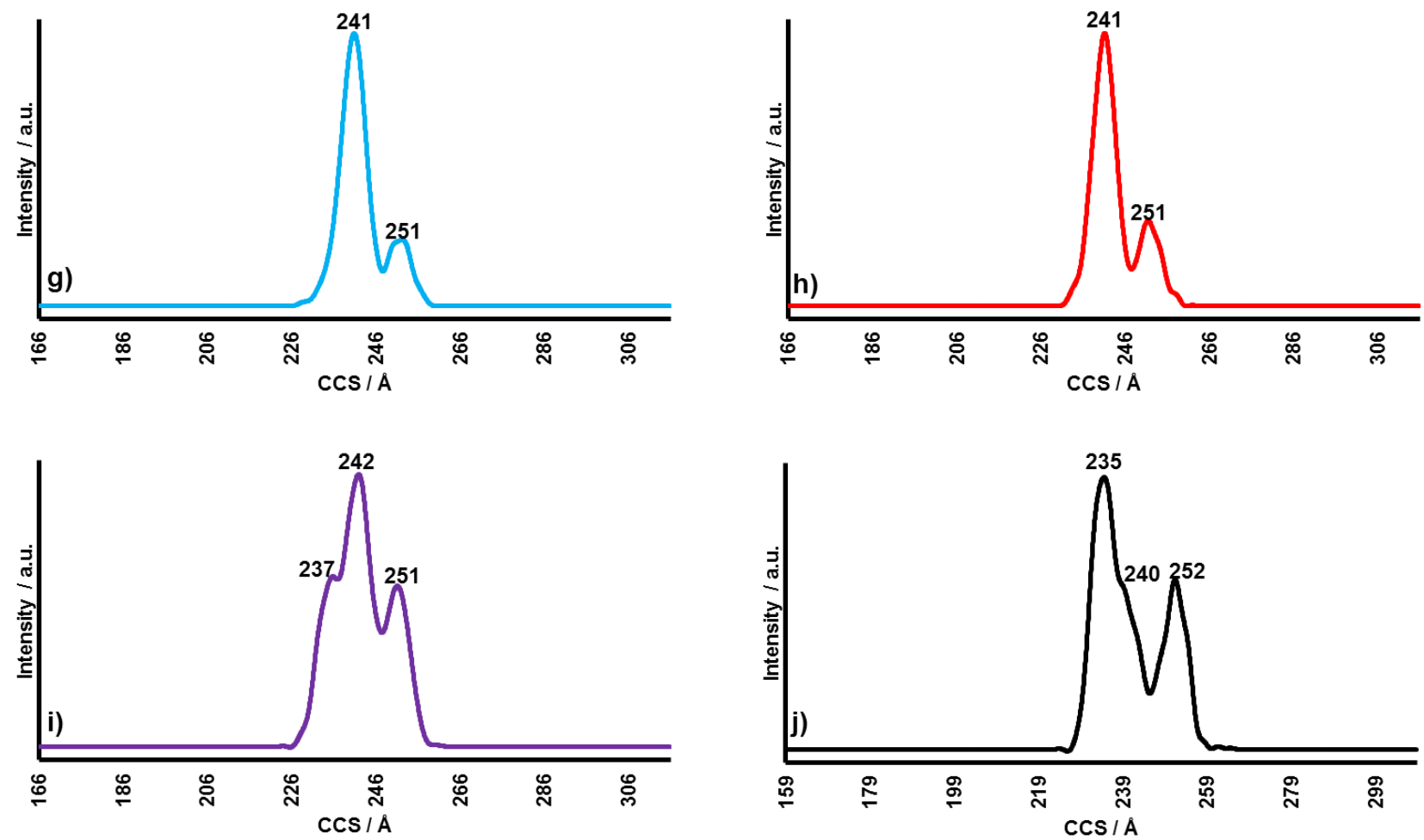

Figure 4. Glycan structures a) F(6)A2BG1 b) F(6)A2B'G1 c) F(6)A2BG1' d) F(6)A3G1 e) F(6)A3G1' f) F(6)A3G1'”. CCSDs for the $\mathrm{m} / z 712$ product ions. g) CCSD for the $\mathrm{m} / z 712$ product ion from fragmentation of isomer $1 \mathrm{~h}$ ) CCSD for the $\mathrm{m} / \mathrm{z} 712$ product ion from fragmentation of isomer 2 i) CCSD for the $\mathrm{m} / \mathrm{z} .712$ product ion from fragmentation of isomer 3 d) CCSD for the $\mathrm{m} / \mathrm{z}, 712$ product ion from fragmentation of isomer 4 . 
CCSD of the product ion $\mathrm{m} / \mathrm{z}, 712$ for the suspected four isomers revealed two distinct classes of isomers. Isomers 1 and 2 which only contained two clear peaks in the CCSD for the $m / z 712$ product ions at $\sim 241 \AA$ and $\sim 251 \AA$ (Figure $4 \mathrm{~g} \& 4 \mathrm{~h}$ ). In contrast the later eluting isomers 3 and 4 contained three clear features (Figure $4 \mathrm{i} \&$ Figure $4 \mathrm{j}$ ). The $\mathrm{m} / z, 712$ CCSDs of isomers 1 and 2 was very similar to those observed for the $\mathrm{F}(6) \mathrm{A} 2 \mathrm{~B}$ species discussed earlier. Isomers 3 and 4 had $m / z 712$ CCSDs that were more similar to those observed for the $\mathrm{F}(6) \mathrm{A} 3$ species. This suggested that isomers 1 and 2 belonged to the F(6)A2BG1 isomers (Figure $4 \mathrm{a}-4 \mathrm{c}$ ) while isomers 3 and 4 belong to the $F(6) A 3 G 1$ isomers (Figure 4d-f). This was also replicated for the $\mathrm{m} / \mathrm{z} 550$ and $\mathrm{m} / \mathrm{z}, 915$ product ions with isomers 1 and 2 having CCSDs similar to $\mathrm{F}(6) \mathrm{A} 2 \mathrm{~B}$, while isomers 3 and 4 had CCSDs which were similar to $F(6) A 3$ (Figure $26 \& 27$ ).

For isomers 1 and 2 we next tried to deduce which of the $\mathrm{F}(6) \mathrm{A} 2 \mathrm{BG} 1$ isomers they belonged to (Figure 4a-4c). Unfortunately there was nothing clear in the CCSDs to suggest which $\mathrm{F}(6) \mathrm{A} 2 \mathrm{BG} 1$ isomers 1 and 2 belonged to. This was also the case for isomers 3 and 4 when trying to deduce which F(6)A3G1 species they each belonged to (Figure 4d-4f). However, given that later eluting peaks in HILIC separation typically have the galactose present on the $\alpha 1,6$ arm of the glycan, and the CCSDs of the $\mathrm{m} / \mathrm{z}$ 550, 712 and 915 product ions we can hypothesize which isomers belong to which peaks. From the CCSDs of product ions we know isomers 1 and 2 are similar to the $\mathrm{F}(6) \mathrm{A} 2 \mathrm{~B}$ isomer. Therefore, isomer 1 is probably the $\mathrm{F}(6) \mathrm{A} 2 \mathrm{BG} 1$ isomer (Figure $\mathrm{S} 4 \mathrm{a}$ ) and isomer 2 is likely the $\mathrm{F}(6) \mathrm{A} 2 \mathrm{BG} 1$ ' isomer (Figure S4c). Isomers 3 and 4 are slightly more difficult to assign but we know form the CCSDs of the $\mathrm{m} / \mathrm{z}, 550,712$ and 915 product ions that they are similar to the $\mathrm{F}(6) \mathrm{A} 3$ isomer. Therefore isomer 3 is probably the F(6)A3G1 isomer (Figure 4d) while isomer 4 could be a combination of $\mathrm{F}(6) \mathrm{A} 3 \mathrm{G} 1$ ' and/or F(6)A3G1' ' isomers (Figure $4 \mathrm{e}$ \& 4f).

To try help further determine which of the $\mathrm{F}(6) \mathrm{A} 3 \mathrm{G} 1$ isomers that isomer 3 and 4 corroborated to, we performed a subtraction analysis on the CCSDs of the $m / z 712$ product ions observed during glycan sequencing. Initially we tried to subtract the $F(6) A 3$ CCSD of the $m / z 712$ product ion from both isomer 3 and 4's $m / z$ 712 product ion CCSDs. This did not reveal any clear indications of which isomer the 3 and 4 belonged to. We therefore tried to subtract the CCSDs of 3 and 4 from each other. This time we saw two clear peaks at $\sim 234 \AA$ and $\sim 242 \AA$ (Figure S28). This was interesting as these two peaks were similar to the differences we observed for the F(6)A2G1 isomers discussed previously. Most notable being the peak at $\sim 234 \AA$ in the subtraction CCSD being similar to the $\mathrm{F}(6) \mathrm{A} 2 \mathrm{G} 1$ ' isomer (Figure S28). This subtraction analysis therefore further reinforced that isomer 4 is probably the F(6)A3G1' and/or F(6)A3G1" isomer (Figure 4e \& 4f) while isomer 3 is probably the $\mathrm{F}(6) \mathrm{A} 3 \mathrm{G} 1$ isomer (Figure 4d). Further research to distinguish between $\mathrm{F}(6) \mathrm{A} 3 \mathrm{G} 1$ ' and $\mathrm{F}(6) \mathrm{A} 3 \mathrm{G} 1$ ', is required.

These results highlight that it is possible to deduce some of the glycan motifs of unknown glycan isomers by comparing the glycan sequencing IMS-MS/MS data of unknown glycans with glycan sequencing IMS-MS/MS data of known isomers. Further work is needed to improve deconvolution of the IMS-MS/MS glycan sequencing data for complex and branched glycan isomers such as F(6)A2BG1 and F(6)A3G1 with data becoming much more difficult to interpret with the increasing complexity of the glycans. These results also show the limited scope of intact IMSMS analysis for glycan isomer identification especially when dealing with unknown or difficult to deduce glycan isomers within a complex sample.

\section{Interactive Database Containing IMS Glycan Data.}

We have mostly discussed identification of isomeric glycans, however we have also recorded data for other structures such as $\mathrm{F}(6) A 2, F(6) A 2 G 2, F(6) A 2 G 2 S 2$ etc., which usually have just one isomer. We could not fit all this data into this single manuscript therefore, we have begun uploading some of our additional data and data discussed within this manuscript onto a small easy to access interactive database for use by the scientific community. We invite people to view this data here.

\section{Conclusion}

Glycans' are difficult biomolecules to characterize owing to their unique branching, composition and isomerism. With this study, we have described the exploitation of different attributes of the glycan as measured by a LC-IMS-MS(/MS) setup namely, their HILIC behavior, CCSDs of intact glycans and also CCSDs of their product ions to comprehensively differentiate glycan isomers and increase the accuracy of their identification. Glycan fragments and their associated CCSDs are ubiquitous attributes that can be found within a glycan analysis and also their glycopeptide counterparts, provided that the analysis is performed in positive ion mode on the mass spectrometer. Furthermore, glycans which share similar structural motifs but are not isomers (such as $\mathrm{F}(6) \mathrm{A} 3$ and $\mathrm{F}(6) \mathrm{A} 3 \mathrm{G} 1$ ), can share common features in the CCSD during IMS-MS/MS glycan sequencing analysis and this can help in the correct identification of the glycans. This approach lends itself to the concept of glycosequencing whereby accurate structural assignment is possible where the identification of the complex molecule is substantiated by the constituent fragments that are unique to the molecule. In publishing our collection of CCSD data we hope not only to accelerate the identification of glycan isomers, but also facilitate further contributions to identifying unique glycans currently not described in databases.

\section{ASSOCIATED CONTENT}

\section{Supporting Information}

PDF Supporting Information (Figures and Methodology).

\section{AUTHOR INFORMATION}

\section{Corresponding Author}

*Sabine Flitsch: sabine.flitsch@ machester.ac.uk

*Terry Nguyen-Khuong: terry_nguyen_khuong@bti.a-star.edu.sg

\section{Author Contributions}

These authors contributed equally.

\section{Notes}

The authors declare no competing financial interests.

\section{ACKNOWLEDGMENT}

This paper was funded by ARAP scholarship and GlycoSing. Special thanks to those at Water Corperation especially Han Wang and Will Eagles who helped maintain the Synapt during the studies. Also a special thanks to all those at A*STAR BTI Analytics group and Animal Cell Technology group who provided support and advice throughout this study.

\section{REFERENCES}

(1)
Varki, A. Biological Roles of Glycans. Glycobiology 2017, 27 (1), 3-49.

Vliegenthart, J. F. G. The Impact of Defining Glycan Structures. Perspect. Sci. 2017, 11, 3-10.

Seeberger, P. H.; Cummings, R. D. Glycans in Biotechnology 
and the Pharmaceutical Industry. Essentials Glycobiol. 3rd Ed. 2017, Chapter 57.

Zhang, P.; Woen, S.; Wang, T.; Liau, B.; Zhao, S.; Chen, C. Yang, Y.; Song, Z.; Wormald, M. R.; Yu, C.; Rudd, P. M. Challenges of Glycosylation Analysis and Control: An Integrated Approach to Producing Optimal and Consistent Therapeutic Drugs. Drug Discov. Today 2016, 21 (5), 740-765. Dekkers, G.; Treffers, L.; Plomp, R.; Bentlage, A. E. H.; Boer M. de; Koeleman, C. A. M.; Lissenberg-Thunnissen, S. N.; Visser, R.; Brouwer, M.; Mok, J. Y.; Matlung, H.; van den Berg, T. K.; van Esch, W. J. E.; Kuijpers, T. W.; Wouters, D.; Rispens, T.; Wuhrer, M.; Vidarsson, G. Decoding the Human Immunoglobulin G-Glycan Repertoire Reveals a Spectrum of Fc-Receptor- and Complement-Mediated-Effector Activities. Front. Immunol. 2017, 8 (887).

(6) Reusch, D.; Tejada, M. L. Fc Glycans of Therapeutic Antibodies as Critical Quality Attributes. Glycobiology 2015, 25 (12), 1325-1334.

(7) Chinuki, Y.; Morita, E. Alpha-Gal-Containing Biologics and Anaphylaxis. Allergol. Int. 2019, 68 (3), 296-300.

(8) Ruhaak, L. R.; Xu, G.; Li, Q.; Goonatilleke, E.; Lebrilla, C. B. Mass Spectrometry Approaches to Glycomic and Glycoproteomic Analyses. Chem. Rev. 2018, 118 (17), 78867930.

(9) Hajba, L.; Csanky, E.; Guttman, A. Liquid Phase Separation Methods for N-Glycosylation Analysis of Glycoproteins of Biomedical and Biopharmaceutical Interest. A Critical Review. Anal. Chim. Acta 2016, 943, 8-16.

(10) Veillon, L.; Huang, Y.; Peng, W.; Dong, X.; Cho, B. G. Mechref, Y. Characterization of Isomeric Glycan Structures by LC-MS/MS. Electrophoresis 2017, 38 (17), 2100-2114.

(11) Adamczyk, B.; Tharmalingam-Jaikaran, T.; Schomberg, M.; Szekrényes, Á.; Kelly, R. M.; Karlsson, N. G.; Guttman, A.; Rudd, P. M. Comparison of Separation Techniques for the Elucidation of IgG N-Glycans Pooled from Healthy Mammalian Species. Carbohydr. Res. 2014, 389 (1), 174-185.

(12) Walsh, I.; Nguyen-khuong, T.; Wongtrakul-kish, K.; Taron, C. H.; Tay, S. J.; Chew, D.; Jose, T.; Rudd, P. M. Structural Bioinformatics GlycanAnalyzer: Software for Automated Interpretation of $\mathrm{N}$-Glycan Profiles after Exoglycosidase Digestions. Bioinformatics 2019, 35 (4), 688-690.

(13) Garner, B.; Merry, A. H.; Royle, L.; Harvey, D. J.; Rudd, P. M.; Thillet, J. Structural Elucidation of the N- and O-Glycans of Human Apolipoprotein(a). Role of O-Glycans in Conferring Protease Resistance. J. Biol. Chem. 2001, 276 (25), 2220022208.

(14) Hofmann, J.; Pagel, K. Glycan Analysis by Ion Mobility-Mass Spectrometry. Angew. Chemie - Int. Ed. 2017, 56 (29), 8342 8349.

(15) Gabelica, V.; Marklund, E. Fundamentals of Ion Mobility Spectrometry. Curr. Opin. Chem. Biol. 2018, 42, 51-59.

(16) Hinneburg, H.; Hofmann, J.; Struwe, W. B.; Thader, A.; Altmann, F.; Varón Silva, D.; Seeberger, P. H.; Pagel, K.; Kolarich, D. Distinguishing N-Acetylneuraminic Acid Linkage Isomers on Glycopeptides by Ion Mobility-Mass Spectrometry. Chem. Commun. 2016, 52 (23), 4381-4384.

(17) Harvey, D. J.; Scarff, C. A.; Edgeworth, M.; Pagel, K.; Thalassinos, K.; Struwe, W. B.; Crispin, M.; Scrivens, J. H. Travelling-Wave Ion Mobility Mass Spectrometry and Negative Ion Fragmentation of Hybrid and Complex N-Glycans. J. Mass Spectrom. 2016, 51 (11), 1064-1079.

(18) Harvey, D. J.; Watanabe, Y.; Allen, J. D.; Rudd, P.; Pagel, K. Crispin, M.; Struwe, W. B. Collision Cross Sections and Ion Mobility Separation of Fragment Ions from Complex NGlycans. J. Am. Soc. Mass Spectrom. 2018, 29 (6), 1250-1261.

(19) Gaunitz, S.; Nagy, G.; Pohl, N. L. B.; Novotny, M. V. Recent Advances in the Analysis of Complex Glycoproteins. Anal. Chem. 2017, 89 (1), 389-413.

(20) Nishikaze, T.; Kawabata, S. I.; Tanaka, K. Fragmentation Characteristics of Deprotonated N-Linked Glycopeptides: Influences of Amino Acid Composition and Sequence. J. Am. Soc. Mass Spectrom. 2014, 25 (6), 988-998.

(21) Glaskin, R. S.; Khatri, K.; Wang, Q.; Zaia, J.; Costello, C. E. Construction of a Database of Collision Cross Section Values for Glycopeptides, Glycans, and Peptides Determined by IM-
(36) Lee, K. J.; Lee, S. M.; Gil, J. Y.; Kwon, O.; Kim, J. Y.; Park, S. J. N -Glycan Analysis of Human a 1-Antitrypsin Produced in Chinese Hamster Ovary Cells. Glycoconj. J. 2013, 30 (5), 537547.

MS. Anal. Chem. 2017, 89 (8), 4452-4460.

Mucha, E.; Stuckmann, A.; Marianski, M.; Struwe, W. B.; Meijer, G.; Pagel, K. In-Depth Structural Analysis of Glycans in the Gas Phase. Chem. Sci. 2019, 10 (5), 1272-1284.

Consortium, T. U. UniProt: A Worldwide Hub of Protein Knowledge. Nucleic Acids Res. 2019, 47 (D1), D506-D515

Gray, C. J.; Thomas, B.; Upton, R.; Migas, L. G.; Eyers, C. E.; Barran, P. E.; Flitsch, S. L. Applications of Ion Mobility Mass Spectrometry for High Throughput, High Resolution Glycan Analysis. Biochim. Biophys. Acta - Gen. Subj. 2016, 1860 (8), 1688-1709.

Both, P.; Green, A. P.; Gray, C. J.; Šardzík, R.; Voglmeir, J.; Fontana, C.; Austeri, M.; Rejzek, M.; Richardson, D.; Field, R. A.; Widmalm, G.; Flitsch, S. L.; Eyers, C. E. Discrimination of Epimeric Glycans and Glycopeptides Using IM-MS and Its Potential for Carbohydrate Sequencing. Nat Chem 2014, 6 (1), $65-74$.

Gray, C. J.; Migas, L. G.; Barran, P. E.; Pagel, K.; Seeberger, P. H.; Eyers, C. E.; Boons, G.-J.; Pohl, N. L. B.; Compagnon, I.; Widmalm, G.; Flitsch, S. L. Advancing Solutions to the Carbohydrate Sequencing Challenge. J. Am. Chem. Soc. 2019, 141 (37), 14463-14479.

Pallister, E. G.; Choo, M. S. F.; Tai, J.-N.; Leong, D. S. Z.; Tang, W.-Q.; Ng, S.-K.; Huang, K.; Marchesi, A.; Both, P.; Gray, C.; Rudd, P. M.; Flitsch, S. L.; Nguyen-Khuong, T. Exploiting the Disialyl Galactose Activity of A2,6Sialyltransferase from Photobacterium Damselae To Generate a Highly Sialylated Recombinant $\alpha$-1-Antitrypsin. Biochemistry 2019, acs.biochem.9b00563.

Pellegrinelli, R. P.; Yue, L.; Carrascosa, E.; Warnke, S.; Ben Faleh, A.; Rizzo, T. R. How General Is Anomeric Retention during Collision-Induced Dissociation of Glycans? J. Am. Chem. Soc. 2020, jacs.0c00264.

Domon, B.; Costello, C. E. A Systematic Nomenclature for Carbohydrate Fragmentations in FAB-MS/MS Spectra of Glycoconjugates. Glycoconj. J. 1988, 5 (4), 397-409.

Wongtrakul-Kish, K.; Walsh, I.; Sim, L. C.; Mak, A.; Liau, B.; Ding, V.; Hayati, N.; Wang, H.; Choo, A.; Rudd, P. M.; Nguyen-Khuong, T. Combining Glucose Units, $m / z$, and Collision Cross Section Values: Multiattribute Data for Increased Accuracy in Automated Glycosphingolipid Glycan Identifications and Its Application in Triple Negative Breast Cancer. Anal. Chem. 2019, 91 (14), 9078-9085.

Zhao, S.; Walsh, I.; Abrahams, J. L.; Royle, L.; NguyenKhuong, T.; Spencer, D.; Fernandes, D. L.; Packer, N. H.; Rudd, P. M.; Campbell, M. P. GlycoStore: A Database of Retention Properties for Glycan Analysis. Bioinformatics 2018, 34 (18), 3231-3232.

Struwe, W. B.; Pagel, K.; Benesch, J. L. P.; Harvey, D. J.; Campbell, M. P. GlycoMob: An Ion Mobility-Mass Spectrometry Collision Cross Section Database for Glycomics. Glycoconj. J. 2016, 33 (3), 399-404. Woo, J.; Ko, B. J. Validation of Rapi-Fluor Method for Glycan Profiling and Application to Commercial Antibody Drugs. Talanta 2019, 198, 105-110. Fort, S.; Flitsch, S.; Loison, C.; Allouche, A. R.; Compagnon, I. Anomeric Memory of the Glycosidic Bond upon Fragmentation and Its Consequences for Carbohydrate Sequencing. Nat. Commun. 2017, 8 (1).

Seipert, R. R.; Dodds, E. D.; Clowers, B. H.; Beecroft, S. M. German, J. B.; Lebrilla, C. B. Factors That Influence Fragmentation Behavior of N-Linked Glycopeptide Ions. Anal. Chem. 2008, 80 (10), 3684-3692. 
